\title{
GRADUAÇÃO EM ENFERMAGEM: APRENDENDO A APRENDER A REFORMA PSIQUIÁTRICA BRASILEIRA ${ }^{1}$
}

\author{
NURSING GRADUATION: LEARNING HOW TO LEARN THE BRAZILIAN \\ PSYCHIATRIC REFORM
}

Agnes Olschowsky*

Sonia Barros**

OLSCHOWSKY, A.; BARROS, S. Graduação em Enfermagem: Aprendendo A Aprender A Reforma Psiquiátrica Brasileira. Rev. Esc. Enf. USP, v. 33, n. 4, p. 377-83, dez. 1999.

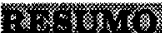

Este trabalho tem como objetivo identificar as mudanças incorporadas no ensino de graduação em enfermagem psiquiatrica. O estudo identifica a preocupação com a atualização do ensino na área, em que a transformação do docente, a participação e a construção de uma nova concepção sobre o saber e as práticas psiquiátricas, possibilitam novas formas de aprender a aprender a reforma psiquiátrica brasileira.

UNITERMOS: Enfermagem Psiquiátrica. Ensino de Enfermagem.

W.

This paper aims at identifying the changes that became part of the theaching of psychiatric nursing. The study points out the concern regardin teaching updating in this area in which the teacher's transformation, participation and the creation of a new concept about psychiatric knowledge and practice make it possible to have new ways to learn how to learn the brazilian psychiatric reform.

UNITERMS: Psychiatric nursing. Nursing teaching.

Nos últimos anos, vivenciamos transformações e questionamentos no campo teórico-conceitual e técnico-assistencial da saúde mental. Essas mudanças têm sido denominadas de Reforma Psiquiátrica, as quais surgiram como movimentos de crítica às instituições psiquiátricas, tendo como alvos principais a exclusão, a cronificação e a violência derivadas do modelo hospitalocêntrico.

O II Congresso dos Trabalhadores de Saúde Mental e a I Conferência Nacional de Saúde Mental, realizados em 1987, foram os cenários que precipitaram a discussão sobre Reforma Psiquiátrica no país. Assim, começava-se a preconizar ações transformadoras, humanizadoras e integrais, que consideram a cidadania e que acontecessem, preferencialmente no espaço extrahospitalar. A questão institucional deixou de ser compreendida como dizendo respeito à racionalização e à modernização das instituições existentes, passando para a necessidade de criar novos lugares de acolhimento e tratamento (BEZERRA JR., 1994).

Essas mudanças no padrão de assistência à saúde mental e a necessidade de novas abordagens institucionais e sociais, recolocam para enfermagem psiquiátrica e em saúde mental a discussão de sua prática assistencial e educacional.

Desse modo, enquanto docentes universitários, percebemos nossa responsabilidade com a formação do enfermeiro bem como a complexidade do processo de ensino, mais especificamente, do ensino de enfermagem psiquiátrica, apontando para uma necessidade de estarmos atentos e flexíveis para os novos conhecimentos e novas práticas, possibilitando assim, uma interação entre a teoria e a prática.

1 Trabalho apresentado na Disciplina Evolução Histórico-Social da Assistência em Saúde Mental do Programa de PósGraduação da Escola de Enfermagem da Universidade de São Paulo (EEUSP).

- Enfermeira, Professora Assistente da Universidade Federal do Rio Grande do Sul, Doutoranda da EEUSP.

* Professora Doutora da EEUSP, coordenadora da disciplina Evolução Histórico Social da Assistência em Saúde mental. 
WALDOW (1989) em suas reflexões sobre o ensino da enfermagem referiu que os profissionais que temos formado, não são considerados satisfatórios pelo mercado. Identifica um sentimento de insatisfação compartilhado por alunos, docentes e profissionais da área, evidenciado na insegurança e na falta de habilidade tanto no "fazer" como no "pensar" enfermagem. Aponta para a necessidade de análise, reflexão e avaliação como elementos obrigatórios no dia-dia dos docentes, pois são responsáveis pela formação do enfermeiro. No processo de ensinoaprendizagem, refere que o conteúdo programático, em geral, tem se reduzido a planos de ensino teóricos desarticulados da prática.

Pensamos que o processo de ensinar não é neutro, representa os diferentes grupos que o compõe, com suas idéias e tendências, inseridos numa realidade social, política e econômica. Assim, identificamos no ensino de enfermagem uma preocupação em pensar/repensar como essa prática tem acontecido e, desse modo flexibilizar os descompassos entre a formação profissional e a sua utilização no mercado de trabalho. Os trabalhos de ALCÂNTARA (1963); GERMANO (1985); LIMA (1993); MENDES (1996), entre outros, referendam a inquietação da área com o processo de formação profissional.

Essas reflexões sobre a formação do enfermeiro repercutem no ensino de enfermagem psiquiátrica.

$\mathrm{Na}$ pesquisa sobre a prática de enfermagem psiquiátrica, realizada por ROCHA (1994), os enfermeiros entrevistados informaram ter recebido uma formação razoável ou boa em psiquiatria em seus cursos de graduação. No entanto, não identificaram com clareza qual o seu papel, levando a autora a afirmar que durante a sua formação o enfermeiro é direcionado para o desempenho de atividades técnicas bem definidas e claras, mas, ao atuar na área psiquiátrica, onde coexistem diferentes vertentes teóricas, dele vão ser exigidos modos de assistência que não lhe foram fornecidas nem na formação e nem na prática institucional.

BARROS (1996), ao analisar a relação entre o processo de ensinar e o processo de aprender da enfermagem psiquiátrica, apontou para o "distanciamento entre a prática assistencial e o saber produzido na academia, sendo possível também afirmar que o enfermeiro tem tido dificuldade para definir seu trabalho frente às novas diretrizes da assistência psiquiátrica".

Pensamos que o ensino de enfermagem psiquiátrica contribui na formação do enfermeiro, sendo um dos espaços que procura ampliar o processo de formação profissional e, propondo-se também, a contribuir na qualidade da assistência de enfermagem, buscando sua transformação.
Refere DEMO (1994), o ensino tem como desafio construir condições para aprender a aprender, para saber pensar e formar a capacidade de participar. Não serve apenas para pensar relações, armazenar informações, mas, especificamente, para fazer alternativas, mudar a história, humanizar a realidade.

Para melhor entendimento do objetivo deste trabalho, consideramos oportuno algumas considerações sobre a reforma psiquiátrica e o ensino da enfermagem psiquiátrica.

No Brasil, a atual concepção de reforma psiquiátrica caracteriza-se pela crítica ao saber psiquiátrico. A desinstitucionalização tem sido entendida como desospitalização, desassistência e desconstrução, abrindo diferentes possibilidades para o campo da reforma psiquiátrica na forma do lidar prático e teórico desta proposta (AMARANTE, 1996).

Refere AMARANTE (1996), que a reforma psiquiátrica, entendida como um conjunto de medidas de desospitalização, aponta para transformações administrativas, partindo do pressuposto que a reforma implica na correta aplicação do saber e das técnicas psiquiátricas.

Entendida como desassistência, proporciona a idéia de abandono dos doentes à própria sorte ou simples envio para fora dos hospitais como se as políticas de desinstitucionalização não significassem a substituição do modelo hospitalar por outras modalidades de assistência e cuidado.

A desinstitucionalização entendida como desconstrução pode ser definida como estratégias de transformações que buscam soluções de questões a um só tempo teóricas, políticas, culturais e sociais. Assim, "o projeto de desinstitucionalização voltase para a superação do ideal de positividade absoluta da ciência moderna em sua racionalidade de causa-efeito, para voltar-se para a invenção da realidade enquanto um processo histórico" (AMARANTE, 1996:24). E, é nessa tendência que a reforma psiquiatrica brasileira busca sua orientação.

Retomando a história da psiquiatria, BERCHERIE (1989) afirma que a psiquiatria clínica e a instituição psiquiátrica nasceram com Pinel, em 1793, quando a observação empírica dos fenômenos da realidade foram a base para o conhecimento científico. Desse modo, conhecer a loucura era observar, descrever, comparar e classificar, passando assim, a ser conceituada como doença e ser objeto da medicina.

$\mathrm{Na}$ época clássica, os hospitais eram os locais de recolhimento e hospedagem para os marginais: leprosos, ladrões, prostitutas, vagabundos, loucos, aqueles que representavam ameaça à lei e à ordem social. $O$ internamento do louco referia-se à ausência de razão e não a critérios de ordem patológica. Pinel, com a instituição 
da doença mental, levantou a possibilidade de tratamento e cura da loucura*, através do tratamento moral** . A internação passou a ter caráter médico, e quando internado o louco era vigiado, julgado, responsabilizado, corrigido e reprimido (FOUCAULT, 1987).

O processo de institucionalização da doença mental e a organização do espaço hospitalar inauguraram uma prática centrada na assistência e na tutela. Pinel ao liberar os loucos das correntes, possibilitou uma melhoria na qualidade das condições de assistência ao doente mental, mas acorrentou-os como objeto de saberes e práticas médicas, dirigindo sua atenção para os sinais e sintomas construídos no corpo doente (CASTEL, 1991).

A loucura apropriada pelo discurso médico, tornou-se doença mental. A desinstitucionalização como desconstrução, propõe uma desmontagem desse paradigma clássico, bem como a possibilidade de construir e inventar novas perspectivas de vida e subjetividade para os loucos. Não implica na rejeição de suas expressões orgânicas, e/ou psicológicas e/ou culturais mas, sua existência não significa que o fenômeno, em sua totalidade e exclusividade, seja físico, ou psicológico ou social (AMARANTE, 1996).

Assim, afirma AMARANTE (1996), acentua-se a reflexão sobre a psiquiatria enquanto instrumento de saber, poder, controle e segregação. É preciso colocar a doença mental entre parênteses, ou seja, ocupar-se de tudo aquilo que se construiu em torno da doença, resgatando a dimensão humana da pessoa doente. Em termos institucionais, coloca-se em questão a função terapêutica, denunciando sua prática alienante e violenta, baseada em noções de periculosidade, irrecuperabilidade e incompreensibilidade da doença mental.

Conforme AMARANTE (1995), a reforma psiquiátrica brasileira como processo, inicia-se em fins da década de 1970, com o Movimento dos Trabalhadores em Saúde Mental (MTSM), denunciando o sistema nacional de assistência psiquiátrica, que incluía torturas, corrupções e fraudes. É naquele momento, que começa a constituir-se um pensamento crítico sobre a natureza e a função social das práticas médicas e psiquiátricopsicológicas.

A I Conferência Nacional de Saúde Mental, em 1987, iniciou a trajetória da desinstitucionalização ou da desconstrução/invenção. "A questão da loucura e do sofrimento psíquico deixa de ser exclusividade dos médicos, administradores e técnicos de saúde mental para alcançar o espaço das cidades, das instituições e da vida dos cidadãos, principalmente daqueles que as experimentam em suas vidas concretas"(AMARANTE, 1995).
Essas transformações da assistência psiquiátrica, repercutem na enfermagem psiquiátrica, enquanto agente dessa prática.

FERNANDES (1982), ROCHA (1994) e BARROS (1996) relataram, em seus estudos, a história da enfermagem psiquiátrica no país. A assistência de enfermagem, no período colonial, era responsabilidade da Igreja e tinha um caráter caritativo, sendo realizada pelas freiras, leigos e ex-pacientes. Os loucos eram recolhidos nos porões das Santas Casas de Misericórdia, onde sofriam espancamentos e contenções.

Desde a inauguração do Hospício Pedro II, há referências quanto à participação dos enfermeiros, orientados a prestar uma assistência com carinho e paciência e, ao mesmo tempo, responsáveis pela ordem do hospício, usando medidas disciplinadoras.

Em 1890, o hospício passou a ser responsabilidade do Estado e os médicos assumiram sua direção. As religiosas, responsáveis pela enfermagem deixaram o asilo, devido incompatibilidade com diretores, sendo contratadas enfermeiras francesas para criar, junto ao hospício, uma escola para formar enfermeiros em psiquiatria, sendo então, fundada a Escola Profissional de Enfermeiros e Enfermeiras no Hospício Nacional de Alienados, primeira tentativa de sistematização do ensino de enfermagem.

Entretanto, o ensino da enfermagem moderna, de acordo com os princípios de Florence Nightingale, deu-se em 1923, com a fundação da Escola de Enfermeiros do Departamento Nacional de Saúde Pública, que mais tarde passou a chamar-se Escola de Enfermeiras D. Ana Neri.

FERNANDES (1982), em sua pesquisa sobre o ensino da enfermagem psiquiátrica no Brasil, referiu que a Lei 775/49, determinou a obrigatoriedade da disciplina de "Enfermagem Psiquiátrica" nos cursos de graduação. Relata que no período de 1930/1964 a ênfase do ensino era dada aos aspectos clínicos da doença mental e às terapêuticas biológicas, centradas no hospital. No final dos anos 50, apareceram, em alguns programas, os reflexos da psicanálise (aspectos psicológicos do comportamento humano e compreensão da conduta patológica), mas as atividades de estágio continuaram sendo as tradicionais, como higiene pessoal, alimentação, administração de medicamentos e manejo de pacientes agitados.

Outro avanço deu-se no período de 1964/1980, no qual foram introduzidos conteúdos da psiquiatria preventiva, abordando os aspectos de desenvolvimento da personalidade, atenção à família e comunidade, assistência aos diversos transtornos mentais e uso de psicofármacos. Os estágios continuavam centrados nos hospitais e os ambulatórios serviam de local de observação da sintomatologia dos pacientes.

\footnotetext{
- Loucura é entendida como alienação, um estado de contradição da razão, ou seja, um estado de privação de liberdade, de perda do livre arbitrio (AMARANTE,1996).

- Tratamento moral caracteriza-se pelo isolamento do mundo exterior, pela separação dos diferentes tipos de enfermidades em locaisdistintos e pelo regime disciplinar como um trabalho terapêutico (AMARANTE, 1996).
} 
$\mathrm{Na}$ análise dos programas de ensino, a autora constatou que as mudanças ocorridas não tinham consistência, pois a maior parte da carga horária continuava centrada na psiquiatria organicista e biológica e os estágios continuavam sendo realizados nos hospitais. Ou seja, apesar do ensino de enfermagem psiquiátrica ser marcado por transformações oriundas da ampliação e expansão da rede hospitalar, pelo desenvolvimento e expansão dos psicofármacos e pelas propostas de comunidade terapêutica, psiquiatria preventiva e social, ele continuou predominantemente tradicional, persistindo no preparo dos profissionais de acordo com os interesses econômicos vigentes em cada momento histórico.

SILVA (1991), analisando o ensino de enfermagem psiquiátrica da Grande São Paulo, na década de 90, constatou a manutenção da ênfase no aspecto curativo e nas atividades práticas hospitalares.

O Seminário Nacional de Enfermagem em Saúde Mental, realizado em 1994, que tinha entre seus objetivos verificar quais aspectos da reforma psiquiátrica estavam sendo contemplados nos currículos de graduação, identificou a existência de um movimento em direção aos princípios deste movimento, mas que estas experiências não revelavam mudanças importantes na assistência (BARROS, 1996).

As mudanças no ensino da enfermagem psiquiátrica refletem, em parte, mudanças na realidade brasileira nas diferentes épocas e articuladas a fatores econômicos, políticos e sociais. Identifica-se, aí, uma transformação no discurso, na teoria, mas a prática assistencial pouco tem mudado.

Frente a isso, cabe uma discussão ética sobre o ensino: é bom? é ruim? é certo? é errado? onde se quer chegar? para que? para quem? É preciso usar o conhecimento/ensino num espaço de permanente elaboração, fazendo um intercâmbio com as diferentes práticas e histórias.

A temática desse estudo diz respeito às reflexões sobre nossa prática docente na área de enfermagem em saúde mental e psiquiátrica, questionando a participação e a responsabilidade dos docentes dessa área como elementos chaves no processo pedagógico. Temos por objetivo, neste trabalho, identificar as mudanças incorporadas no ensino de graduação em enfermagem psiquiátrica frente à propostas da reforma psiquiátrica brasileira e, desse modo estarmos contribuirmos para o debate da reforma psiquiátrica brasileira.

\section{REFERENCIAL TEÓRICO-METODOLÓGICO}

Propomos para este trabalho uma abordagem com base no referencial histórico-estrutural, no qual a realidade estudada é entendida como histórica, ou seja, que se constrói e se transforma pelas ações, negociações, conflitos e tomada de consciência dos atores nele envolvidos em um tempo dado.
A enfermagem e o ensino de enfermagem psiquiátrica são consideradas como prática social, em constante movimento e mudança, que influenciam seus agentes e por eles é influenciada, nas condições concretas da instituição e da sociedade.

Dessa forma, o ensino de graduação em enfermagem psiquiátrica é entendido como uma dimensão constitutiva de um trabalho coletivo, que se constitui e se transforma para satisfazer carecimentos e necessidades postos pela sociedade. É uma prática histórica, dinâmica, estruturada por relações sociais, por atores em condições econômicas, políticas e culturais específicas. Essas relações tornam-se concretas na prática institucional, nas ações dos docentes e nas concepções que têm sobre si, seu trabalho e seu lugar na sociedade.

Para coleta de dados foram realizadas entrevistas com a totalidade de docentes (sete) que ministravam o ensino de enfermagem psiquiátrica, do curso de graduação em Enfermagem numa Universidade Pública do país.

Do ponto de vista operacional essa amostra é representativa, pois segundo MINAYO (1993), a amostragem da pesquisa qualitativa tem preocupação maior com o aprofundamento e abrangência de compreensão, seja de um grupo social, de uma instituição, de uma política ou de uma representação e menor com a generalização. $O$ critério, portanto, não é quantitativo.

A disciplina Enfermagem Psiquiátrica, ministrada pelos docentes entrevistados, é oferecida para os alunos do terceiro ao sexto semestre do curso de graduação. Tem carga horária total de cento e oitenta horas, sendo sessenta horas teóricas e, as demais teórico-práticas, nas quais são realizados os estágios.

Foram realizadas entrevistas semi-estruturadas, nas quais as perguntas abertas e fechadas servem de orientação para o entrevistador e não como um controle de informações, possibilitando aos entrevistados falarem espontaneamente sobre o assunto (MINAYO, 1993).

As entrevistas foram gravadas e transcritas, para posterior análise, sendo considerado os aspectos éticos do consentimento e sigilo dos entrevistados.

Para apreender o ponto de vista dos entrevistados sobre o objetivo enfocado nessa pesquisa, foi colocada a seguinte questão norteadora: como ensinar, considerando o movimento da reforma psiquiátrica?; sem prejuízo de outras questões que se fizeram necessárias na construção desse estudo.

Segundo a orientação de MINAYO (1993), na análise dos depoimentos foram observados os seguintes passos: ordenação dos dados, classificação e análise final.

Os autores desta pesquisa entendem o conhecimento como uma aproximação da realidade, na qual sua apreensão não é simples e nunca chega a ser completa, pois a realidade é sempre mais rica do que qualquer forma de representá-la ou de estudá-la. 


\section{ANÁLISE DOS DADOS}

Os docentes entrevistados, ao responderem a pergunta: como ensinar, considerando o movimento da reforma psiquiátrica? revelaram suas idéias, sentimentos e condutas sobre o processo educacional na área de enfermagem psiquiátrica, proporcionando uma visão da problemática para implementar mudanças ou não no referido processo.

Uma das questões apontadas pelos entrevistados, refere-se a importância da dinamicidade do ensino, evidenciada na transcrição abaixo.

"Acho que é um movimento. Não tem um saber constituido pronto, acabado. $O$ ensino, ele carrega toda essa ondulação. $\dot{E}$ uma construção e uma informação constante, uma reciclagem, uma leitura, uma discussão com os pares."

Transparece, aí, a idéia de ensino como um desafio, como capacidade de construir/reconstruir conhecimentos com os diferentes atores envolvidos e, não aprisionado a formas cristalizadas do saber $e$ da prática.

A construção do processo pedagógico acontece no questionamento e na reflexão sobre os meios, modos, formas e procedimentos de como manejar os saberes e as práticas da enfermagem psiquiátrica inserida na realidade de saúde, especificamente da reforma psiquiátrica.

Outro aspecto levantado pelos participantes do estudo, conforme a frase seguinte, é a necessidade da transformação do docente, na qual como ator responsável pelo processo ensino-aprendizagem precisa exercitar a construção/desconstrução dos seus conhecimentos. Essa tendência de desconstruir, é evidenciada na reforma psiquiátrica, sendo uma de suas orientações teóricas como estratégia na luta de extinção/superação dos manicômios como instituições de violência.

“ (...) não adianta muito mudar conteúdos, mudar local de práticas, se a gente não mudar a postura que está bastante sedimentada. (...) Mudar nossa atitude: é fazer uma reflexão. Quando fiz determinada intervenção, o que usei? que conhecimento eu tinha? (...) É um processo de reflexão contínua. Não é jogar fora os conhecimentos anteriores. $\grave{E}$ superar alguns conhecimentos para construir novos."
Assim, ensinar significa transmitir conhecimentos, experienciar práticas e buscar alternativas, argumentando teoricamente em favor das escolhas. Requer crescimento pessoal e interpessoal. É um processo de relação permanente entre teoria e prática, pensar e agir, planejar e fazer.

Essas mudanças no docente e, conseqüentemente, no ensino são oportunizadas pela participação e pela divulgação da reforma psiquiátrica, evidenciada na afirmação abaixo.

\begin{abstract}
"O primeiro ponto, é não ficar cego ao movimento que está acontecendo. Poder enxergar e estar dentro. $O$ segundo ponto, é poder atuar, estar presente nessas instituições que são alternativas. (...) trazer pessoas para o campo de ensino que experimentaram ou estão envolvidas. (...) o que tem se escrito, precisa ser conhecido."
\end{abstract}

QUINTO NETO (1992) refere sobre a importância de ação política, ou seja, que as ações dos profissionais de saúde mental só avançam ou produzem impacto com a participação destes nos movimentos sociais. Para tal, é necessário formação crítica e capacidade de questionar e intervir.

Ensinar, considerando a reforma psiquiátrica, traduz-se na "construção de uma nova concepção" sobre o saber psiquiátrico e sua prática institucional, como nos mostram as afirmativas seguintes:

\begin{abstract}
"Estamos tentando também construir. Desvincular da idéia de doença, de incapaz, de centrar só no sintoma. (...) Temos instituído campo de estágio fora do âmbito hospitalar: no ambulatório de saúde mental, nas enfermarias de psiquiatria dentro do hospital geral."

"Temos de procurar práticas que são diferenciadas, tendo como objeto o ser humano, não a doença. Tendo, cada vez mais claro, que o nosso processo de trabalho não busca a cura, mas busca qualidade de vida daquela pessoa."

"Uma postura mais aberta. Não é aquela postura de vigilância, aquela postura autoritária e de controle. É uma postura mais de participação, mais de facilitador."
\end{abstract}

A desinstitucionalização recusa uma solução técnica para a loucura enquanto doença, procura aproximar-se da experiência concreta do doente, da sua experiência de sofrimento numa realidade: sua singularidade, sua história, sua cultura, sua vida cotidiana. 
Os participantes deste estudo trazem, também, a necessidade de formação dos profissionais do campo, considerando o projeto de reforma psiquiátrica como um projeto que deve ser coletivo, compartilhado que se só desenvolve na totalidade do trabalho.

\begin{abstract}
"Acho que outra questão é estar capacitando os recursos humanos da rede para essa nova modalidade de atenção. (...) Meu trabalho, nas emergências mostrou que os profissionais que trabalham ali, têm uma atitude negativa com o louco. Então, eles precisam ser trabalhados, capacitados para poder atender."
\end{abstract}

A possibilidade concreta de transformação do ensino de enfermagem psiquiátrica, deve ser orientada pelo princípio de problematizar e dialetizar o processo educacional e a reforma psiquiátrica. Assim, significa uma recusa sistemática do paradigma "doença-cura" e, uma busca de novas formas de tratamento que não devem ser institucionalizadas em regras e ordens cristalizadas. É preciso inventar, construir/ desconstruindo um novo tipo de relação entre a loucura, os técnicos e a sociedade, entendendo o conflito, a diferença como parte desse processo. Precisamos transformar/superar nossa prática, nos desafiar no ato pedagógico, buscando reformar também, nossas verdades, idéias e conhecimentos e, através deste olhar, buscarmos novos modos de agir e ensinar.

\section{CONSIDERAÇÕES FINAIS}

A reforma psiquiátrica brasileira aponta para uma ação transformadora do saber na psiquiatria, ou seja, uma concepção positiva de loucura.

Propõe mudanças no campo teórico-conceitual e técnico-assistencial, olhando este indivíduo doente como uma pessoa singular na sua pluralidade: pessoa que sofre física, psico e socialmente e, que requer acolhimento dos profissionais, familiares e comunidade.

Propõe mudanças do imaginário social e do campo jurídico-político, permitindo que este indivíduo tenha liberdade de ser louco e resgate sua cidadania.

É no movimento dessa realidade, que o ensino de graduação em enfermagem psiquiátrica se constrói/ reconstrói, com conflitos e contradições.

Ensinar, considerando a reforma psiquiátrica, conforme os resultados deste trabalho, traduz-se como a capacidade do docente construir conhecimentos inseridos nesta realidade concreta. Existe uma preocupação com a transformação do saber teórico e prático da psiquiatria, apontando para a necessidade de mudança no ensino dos conteúdos teóricos e práticos da assistência, visando construir e inventar, superando a técnica, enquanto uma ação intervencionista, limitante e estigmatizante.

Assim, é preciso uma ação compromissada para romper barreiras e contribuir com o movimento da Reforma Psiquiátrica, possibilitando construir uma concepção positiva de loucura, ou seja, valorizando idéias, condições de vida e participação dos docentes, pesquisadores, profissionais e usuários dos serviços de saúde mental. É preciso questionar nossos saberes, valores, ações e posturas, resgatando recursos internos e externos para fazer a reforma e, desse modo, reinventarmos o ensino de enfermagem psiquiátrica enquanto parte da reforma psiquiátrica brasileira.

Nessa perspectiva, ensinar é interagir, aproximar e fazer dialogar universos diferentes. $O$ ensino aparece como um desafio, algo em movimento, no qual o processo pedagógico se dá pelo questionamento e pela reflexão das formas de como manejar e utilizar os saberes e as práticas inseridos na realidade de saúde da sociedade.

A construção deste novo ensinar implica na transformação do docente, ou seja, re/olhar seus valores, seus conhecimentos e suas ações. Aprendendo a aprender a reforma psiquiátrica é enfrentar nossas verdades, é efetuar mudanças dentro e fora de nós e, assim, ensinar com compromisso, promovendo as relações de troca e, conseqüentemente, revitalizando/ reformando teoria e prática.

\section{REFERÊNCIAS BIBLIOGRÁFICAS}

ALCÂNTARA, G. A enfermagem moderna como categoria profissional: obstáculos à sua expansão na sociedade brasileira. Ribeirão Preto. 1963. 125p. Tese (Cátedra) Escola de Enfermagem de Ribeirão Preto, Universidade de São Paulo.

AMARANTE, P. (org.) Loucos pela vida: trajetória da reforma psiquiátrica no Brasil. Rio de Janeiro, SDE/ENSP, 1995. O homem e a serpente: outras histórias para a loucura e a psiquiatria. Rio de Janeiro, Fio Cruz, 1996.

BARROS, S. O louco, a loucura e a alienação institucional: o ensino de enfermagem psiquiátrica sub judice. São Paulo, 1996. 202p. Tese (Doutorado) - Escola de Enfermagem, Universidade de São Paulo.

BERCHERIE, P. Os fundamentos da clínica: história e estrutura do saber psiquiátrico. Rio de Janeiro, Zahar, 1989.

BEZERRA JR, B. De médico, de louco todo mundo tem um pouco. $O$ campo psiquiátrico no Brasil dos anos oitenta. In: GUIMARÃES, R.; TAVARES, R. Saúde e sociedade no Brasil: anos oitenta. Rio de Janeiro: Relume/Dumará, 1994, p. 171-91.

CASTEL, R. A ordem psiquiátrica: a idade de ouro do alienismo. 2.ed. Rio de Janeiro, Graal, 1991.

DEMO, P. Educação e qualidade. Campinas, Papirus, 1994. 
FERNANDES, J.D. O ensino de enfermagem e de enfermagem psiquiátrica no Brasil. Salvador, 1982. 111p. Dissertação (mestrado) - Universidade Federal da Bahia.

FOUCAULT, M. História da loucura na idade clássica. 2.ed. São Paulo, Perspectiva, 1987.

GERMANO, R. M. Educação e ideologia da enfermagem no Brasil. São Paulo, Cortez, 1985.

LIMA, M. A. D. S. A formação do enfermeiro e a prática profissional: qual a relação? Rio Grande do Sul, 1993. Dissertação (Mestrado) Faculdade de Educação, Pontifícia Universidade Católica do Rio Grande do Sul.

MENDES, M. M. R. O ensino de graduação em enfermagem no Brasil - entre 1972 e 1994 - mudança de paradigma curricular? 1996, 312p. Tese (Doutorado) - Escola de Enfermagem de Ribeirão Preto, Universidade de São Paulo.
MINAYO, M. C. S. O desafio do conhecimento: pesquisa qualitativa em saúde. 2 ed. São Paulo: Hucitec Abrasco, 1993.

QUINTO NETO, A. A reforma psiquiátrica no Rio Grande do Sul : o direito de tratamento aos direitos de cidadania do doente mental. Saúde Deb. Londrina, n. 37, p. 5-10, 1992.

ROCHA, R. M. Enfermagem psiquiátrica: que papel é este? Rio de Janeiro, Te Corá, 1994.

SILVA, M.C.P. Análise do ensino da disciplina enfermagem psiquiátrica nos cursos de graduação em enfermagem da Grande São Paulo. São Paulo, 1991. 129p. Dissertação (Mestrado) - Escola de Enfermagem, Universidade de São Paulo.

WALDOW, V. R. Reflexões sobre o ensino da enfermagem. Rev.Gaúcha Enf., v. 10, n. 2, p. 41-4, 1989. 